\title{
RESEARCH
}

Open Access

\section{Patterns, trends and determinants of medical opioid utilization in Canada 2005- 2020: characterizing an era of intensive rise and fall}

Wayne Jones ${ }^{1}$, Ridhwana Kaoser ${ }^{1}$ and Benedikt Fischer ${ }^{1,2,3,4^{*}}$ [D

\begin{abstract}
Background: Into the 21st century, the conflation of high rates of chronic pain, systemic gaps in treatment availability and access, and the arrival of potent new opioid medications (e.g., slow-release oxycodone) facilitated strong increases in medical opioid dispensing in Canada. These persisted until post-2010 alongside rising opioidrelated adverse (e.g., morbidity/mortality) outcomes. We examine patterns, trends and determinants of opioid dispensing in Canada, and specifically its 10 provinces, for the years 2005-2020.

Methods: Raw data on prescription opioid dispensing were obtained from a large national community-based pharmacy database (IQVIA/Compuscript), converted into Defined-Daily-Doses/1,000 population/day for 'strong' and 'weak' opioid categories per standard methods. Dispensing by opioid category and formulations by province/year was assessed descriptively; regression analysis was applied to examine possible segmentation of over-time strong opioid dispensing.
\end{abstract}

Results: All provinces reported starkly increasing strong opioid dispensing peaking 2011-2016, and subsequent marked declines. About half reported lower strong opioid dispensing in 2020 compared to 2005, with continuous inter-provincial differences of $>100 \%$; weak opioids also declined post-2011/12. Segmented regression suggests breakpoints for strong opioids in 2011/12 and 2015/16, coinciding with main interventions (e.g., selective opioid delisting, new prescribing guidelines) towards more restrictive opioid utilization control.

Conclusions: We characterized an era of marked rise and fall, while featuring stark inter-provincial heterogeneity in opioid dispensing in Canada. While little evidence for improvements in pain care outcomes exists, the starkly inverting opioid utilization have been associated with extensive population-level harms (e.g., misuse, morbidity, mortality) over-time. This national case study raises fundamental questions for opioid-related health policy and practice.

Keywords: Opioids, Pharmacoepidemiology, Canada, Pain, Utilization, Policy

\footnotetext{
* Correspondence: bfischer@sfu.ca

${ }^{1}$ Centre for Applied Research in Mental Health and Addiction (CARMHA),

Faculty of Health Sciences, Simon Fraser University, Suite 2400, 515 W.

Hastings Street, British Columbia, Vancouver, Canada

${ }^{2}$ Faculty of Medical and Health Sciences, University of Auckland, 85 Park

Road, Auckland 1023 Grafton, New Zealand

Full list of author information is available at the end of the article
}

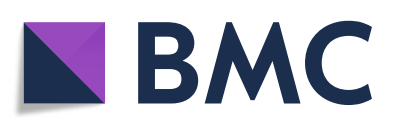

(๑) The Author(s). 2021 Open Access This article is licensed under a Creative Commons Attribution 4.0 International License, which permits use, sharing, adaptation, distribution and reproduction in any medium or format, as long as you give appropriate credit to the original author(s) and the source, provide a link to the Creative Commons licence, and indicate if changes were made. The images or other third party material in this article are included in the article's Creative Commons licence, unless indicated otherwise in a credit line to the material. If material is not included in the article's Creative Commons licence and your intended use is not permitted by statutory regulation or exceeds the permitted use, you will need to obtain permission directly from the copyright holder. To view a copy of this licence, visit http://creativecommons.org/licenses/by/4.0/ The Creative Commons Public Domain Dedication waiver (http://creativecommons.org/publicdomain/zero/1.0/) applies to the data made available in this article, unless otherwise stated in a credit line to the data. 


\section{Introduction}

The transition into the 21st century marked a turning point for chronic pain and related opioid pharmacotherapy in North America, and Canada specifically. There, $20-29 \%$ of the gcomes in the populationeneral population were estimated to experience chronic pain in the early 2000s, however systemic gaps existed in access to and/or effectiveness of available care [1, 2]. More broadly, a vocal socio-medical movement had begun to propagate chronic pain as a neglected 'fifth vital sign', advocating for systematic expansions of improved treatment and care [3, 4], including more generous utilization of opioid pharmacotherapy options then generally considered "safe and efficacious" [1]. Among other barriers, pharmacotherapeutic approaches to chronic pain care were viewed as hindered by many physicians' lack of knowledge and/or hesitation to prescribe available opioid medications for chronic pain [5, 6].

A number of concrete developments facilitated a profound expansion of opioid pharmacotherapy for chronic pain in the early 2000s in Canada. Sequential iterations of national pain care guidelines (updated in 2002) recommended a wider-scale and more generous (e.g., higher doses/long-term) therapeutic utilization of opioid analgesic medications for chronic pain [7]. In addition, new and potent opioid formulations - most notably including 'slow-release' oxycodone (e.g., Oxycontin) - had become available and became widely utilized, alongside other potent semi-/synthetic opioid medications (e.g., fentanyl, hydromorphone) that were increasingly and more generously prescribed in both specialist and general/community practice settings [8-10]. Particularly in the case of Oxycontin, their rising utilization was distinctly boosted by pharmaceutical companies' targeted marketing strategies involving 'peer educators' (i.e., physician representatives) promoting expanded prescribing $[11,12]$.

In these contexts, the population rate of controlled total opioid dispensing in Canada - as reported by the International Narcotics Control Board (INCB) - more than tripled within just one decade, from 8,713 Standardized Defined Daily Doses [S-DDD] in 2000-2002 to 29,743 S-DDD in 2010-12 [13]. During this period, Canada's opioid dispensing rate climbed more steeply than that of the United States (US), the nation featuring the world's highest opioid consumption rate; on this basis, Canada rose to record the world's second-highest opioid consumption rate (after the US) [14]. By 2010, more than one-in-five $(20 \%)$ of Canadian adults reported annual use of pain-related opioid medications [15].

While the benefits for therapeutic pain care quality and outcomes from these extensive increases have remained uncertain, they were associated with rising adverse opioid-related (e.g., mortality and morbidity) outcomes in the population, including increases in nonmedical opioid use and diversion, opioid-related hospitalizations, treatment admissions and poisoning fatalities [15-17]. For example, in Ontario, $6 \%$ of adults and $15 \%$ of high-school students reported non-medical opioid use by 2010 , opioid-related treatment admissions doubled and opioid-related fatalities rose from 366 (2003) to 571 $(2010)$, with approximately $40 \%$ oxycodone-related [ 15 , $18,19]$. By 2010, it was evident that a sort of 'opioid crisis' involving extensive adverse health outcomes in the population -- fuelled by the excessive availability and adverse consequences of prescription opioids -- was unfolding in Canada [8, 20, 21].

While government and other (e.g., medical/regulatory) policy makers and stakeholders had undertaken little to halt the growing opioid-related harms until then, a series of multi-level interventions aiming to restrict opioid availability and harms were implemented post-2010 [22] Among them, slow-release oxycodone formulations were delisted from most provincial formularies across Canada in 2012 [23, 24]. Several provinces introduced (e.g., Ontario in 2012) or ramped up their 'prescription monitoring' systems including opioids in their scope $[25,26]$. A national stakeholder coalition tabled a strategic action plan of proposed measures [2013] to reduce opioidrelated harms [27]. Select regulatory efforts aimed to increase the use of 'safer' (e.g., tamper-resistant/abuse-deterrent) opioid formulations, and to limit high-dose prescribing [23, 28]. Meanwhile, emerging scientific evidence assumed an increasingly cautious and restrained view on the effectiveness and safety of opioid pharmacotherapy especially for chronic pain care [29, 30]. Correspondingly, new Canadian opioid prescribing guidelines (2017), similar to recent US (CDC) counterparts launched in 2016, presented a marked reversal from previous guideline versions and provided direction for a generally much more restrained and cautious ('last resort') approach to opioid pharmacotherapy utilization and practice for pain care [31].

Following these interventions, on overall decline in medical opioid utilization began to unfold. Canada's total opioid utilization peaked at 34,444 S-DDD in 2013-15, and substantively decreased to 19,629 SDDD (-43\%) by 2017-19 [13]. While prescription opioid-related harms (e.g., poisoning fatalities) remained generally steady, expanding availability and use of illicit/synthetic opioid (e.g., fentanyl) products started to shift and accelerate patterns especially of non-medical opioid harms in the years since 2014/15 across Canada [32-34]. In 2018, the federal government established of the Canadian Pain Task Force, with a mandate to assess the state of pain and related care practices and systems in Canada [35]. 
Within these wider contexts, and building on previous related examinations, the present study assesses overall (quantitative \& qualitative) patterns, trends and determinants of medical opioid utilization in Canada and specifically its 10 provinces for the period 2005-2020.

\section{Methods}

The primary data on prescription opioid dispensing in Canada for the period 2005-2020 were derived and computed based on information from the IQVIA Canada Inc. (formerly QuintilesIMS/IMS Brogan) Compuscript database. This database monitors prescriptionbased transactions for branded and generic medications via a representative and stratified sample of about 6,500 (representing about $60 \%$ of the total) retail pharmacies across Canada [36, 37]. Monthly dispensing data is aggregated to provincial totals using a patented geospatial projection methodology, with an estimated sampling error of $5-10 \%$. The Compuscript data do not include non-prescription (e.g., 'over-the-counter' codeine) products, nor cover other (e.g., hospital-based) drug dispensing, yet comprise the far majority (estimated $80 \%+$ ) of total utilization. Similar dispensing data have been used for other population-level pharmacoepidemiologic analyses [38, 39].

Based on previously applied methods, raw prescription opioid dispensing information was obtained by yearly totals for the 10 Canadian provinces (but not including the three Canadian territories, which however only make up $<0.5 \%$ of the Canadian total population) of both the numbers of prescriptions and units dispensed, opioid molecule (codeine, fentanyl, hydrocodone, hydromorphone, meperidine, methadone, morphine, oxycodone, tramadol), and product name (494 unique names included), form and strength information. Data for the different opioid products were matched to defined daily dose (DDD) estimates using the World Health Organization's Anatomical Therapeutic Chemical classification and DDD measurement methodology, defining DDDs as the "... assumed average maintenance dose per day for a drug used for its main indication in adults" [40]. DDD are a standard metric commonly used for comparative drug utilization analysis [41, 42]. Combined with yearly provincial population estimates (obtained from Statistics Canada [43]) the total opioid dispensing data was converted to annual DDDs/per 1,000 population/per day (DDD/1,000/day) estimates for the 10 provinces and Canada total, and furthermore categorized into "strong opioids" (i.e., including fentanyl, hydrocodone, hydromorphone, meperidine, morphine, and oxycodone) and "weak opioids" (i.e., codeine) generally following the WHO 'analgesic ladder' [44, 45]. Methadone, while defined as a strong opioid, was excluded from the analyses since it is primarily used for addiction (i.e., opioid maintenance) treatment, and its dispensing practices are inconsistent and do not allow for comparable estimates across Canada [37].

Database design and data manipulation was conducted using the $\mathrm{R}$ software package, including data plotting for visualization [46]. For descriptive analyses, first, we examined the annual dispensing levels of "strong" (including main individual formulations) and "weak" (codeine) opioid products for Canada and the provinces, 20052020. Second, we computed the intra-provincial ranges of highest and lowest annual strong opioid dispensing values for the study period. Third, towards assessing significant over-time changes in strong opioid dispensing in Canada, we applied a segmented (or 'broken stick') regression analysis [47]. This regression-based method partitions the independent variable into intervals and fits corresponding straight-lines to data interval-subsets (here the 16 annual datapoints of strong opioid dispensing), while identifying possible inter-segmental 'breakpoints' [48, 49]. Akaike information criterion (AIC) values were computed to assess the quality-of-fit for each model. For these analyses, the $\mathrm{R}$ package 'segmented' was used.

\section{Results}

Strong opioids (total) [see Fig. 1 for data visualization] In 2005, the lowest strong opioid dispensing rate was reported by Manitoba (MN;3.9 DDD/1,000/day), and the highest by Ontario (ON;10.1 DDD/1,000/day), translating into an inter-provincial range of difference of $159 \%$.

Between 2005 and 2011, each of the provinces reported substantive increases in their annual rates of strong opioid dispensing, with individual provinces' respective opioid dispensing levels peaking sometime between 2011 and 2016 as follows: British Columbia (BC), Alberta (AB), MN, ON (2011); Nova Scotia (NS), Prince Edward Island (PEI; 2013); Saskatchewan (SK;2014); New Brunswick (NB), Newfoundland (NL;2015); and Quebec (QC;2016). The highest 'peak' value for opioid dispensing was reported by ON (14.2 DDD/1,000/day), and the lowest 'peak' value by QC (6.6 DDD/1,000/day), indicating a total interprovincial range of difference of $115 \%$ for 'peak' levels.

Following their respective 'peak' level years, each of the provinces reported decreases in strong opioid dispensing, declining to - with the exception of two provinces (BC \& PEI) - lowest post-peak level of strong opioid dispensing in 2020. ON reported the proportionally greatest decrease between its respective 'peak' level year in strong opioid dispensing (2011) and 2020 (-54.9\%) whereas PEI (2016-2020) had the correspondingly smallest decrease (-17.8\%). In 2020, the lowest opioid dispensing rate was report by $\mathrm{MN}$ (4.6 DDD/1,000/ day), and the highest rate by $\mathrm{NB}(9.0 \mathrm{DDD} / 1,000 /$ day $)$, translating into an inter-provincial range of difference of 


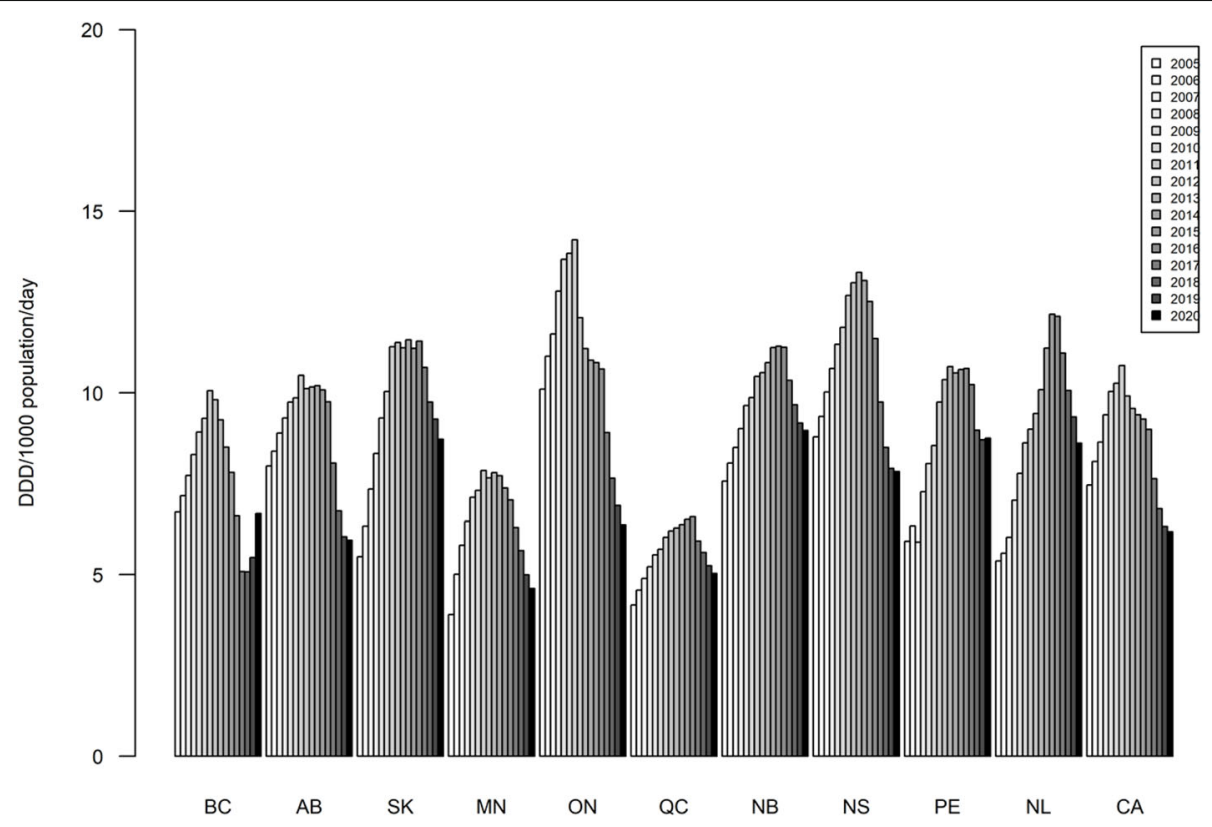

Fig. 1 Annual 'strong opioid' utilization in DDD/1,000 population/day by province and Canada total, 2005-2020

$96 \%$. Four provinces reported same, or lower strong opioid dispensing levels in 2020 compared with 2005.

For intra-provincial variation in annual strong opioid dispensing, NB indicated the smallest range $(49 \%)$ and NL indicated the largest range $(126 \%)$ over the observation period (2005-2020) (see Table 1).

\section{Strong opioids (individual formulations) [see Fig. 2 for data visualization]}

For main individual strong opioid formulations, varying trends and patterns were observed by province.

Table 1 Intra-provincial ranges and percent differences in 'strong opioid' utilization, provinces and Canada total, 2005-2020

\begin{tabular}{llll}
\hline \multirow{2}{*}{ Province } & \multicolumn{3}{l}{ DDD/1000/Day: Years 2005-2020 } \\
\cline { 2 - 4 } & Minimum & Maximum & Difference (\%) \\
\hline BC & 5.1 & 10.1 & $98.3 \%$ \\
AB & 5.9 & 10.5 & $76.2 \%$ \\
SK & 5.5 & 11.5 & $108.8 \%$ \\
MN & 3.9 & 7.9 & $101.7 \%$ \\
ON & 6.4 & 14.2 & $123.2 \%$ \\
QC & 4.2 & 6.6 & $58.3 \%$ \\
NB & 7.6 & 11.3 & $49.2 \%$ \\
NS & 7.8 & 13.3 & $69.9 \%$ \\
PEI & 5.9 & 10.7 & $82.0 \%$ \\
NL & 5.4 & 12.2 & $126.1 \%$ \\
CA & 6.2 & 10.8 & $74.1 \%$ \\
\hline Abbevitons & BC &
\end{tabular}

Abbreviations: $B C$ British Columbia, $A B$ Alberta, $S K$ Saskatchewan, $M N$ Manitoba, ON Ontario, QC Quebec, NB New Brunswick, NS Nova Scotia, PEI Prince Edward Island, NL Newfoundland, CA Canada
For fentanyl, all provinces reported increases in dispensing until 2014/2015 which then inverted to varying levels of decreases. In any given year, the interprovincial levels of fentanyl dispensing varied by at least $100 \%$; half the provinces reported lower fentanyl dispensing rates in 2020 compared to 2005. Hydrocodone has been dispensed almost exclusively in $\mathrm{ON}$ and, at much lower levels, in QC; its utilization in ON was stable until 2011, and then steeply dropped. Hydromorphone (similar to fentanyl) dispensing increased in all provinces to 2015/2016, and subsequently inverted to decrease. While in any given year, hydromorphone dispensing levels inter-provincially varied by at least $100 \%$, each province reported higher hydromorphone dispensing in 2020 as compared with 2005. While some provinces reported increases in morphine dispensing in the early years of observation, other reported mostly decreasing trends; half the provinces indicated lower morphine dispensing levels in 2020 compared with 2005. BC is a noted outlier for both hydromorphone and morphine dispensing, in that it features marked recent increases in dispensing for both recent opioid drugs; its morphine utilization in 2020 is the highest for the total study period. For oxycodone, most provinces reported strong dispensing increases (most of them peaking in 2011) which subsequently inverted to substantive decreases. In each year, the inter-provincial dispensing range for oxycodone differed by at least $200 \%$, while the majority of provinces reported lower oxycodone dispensing levels in 2020 compared with 2005. 


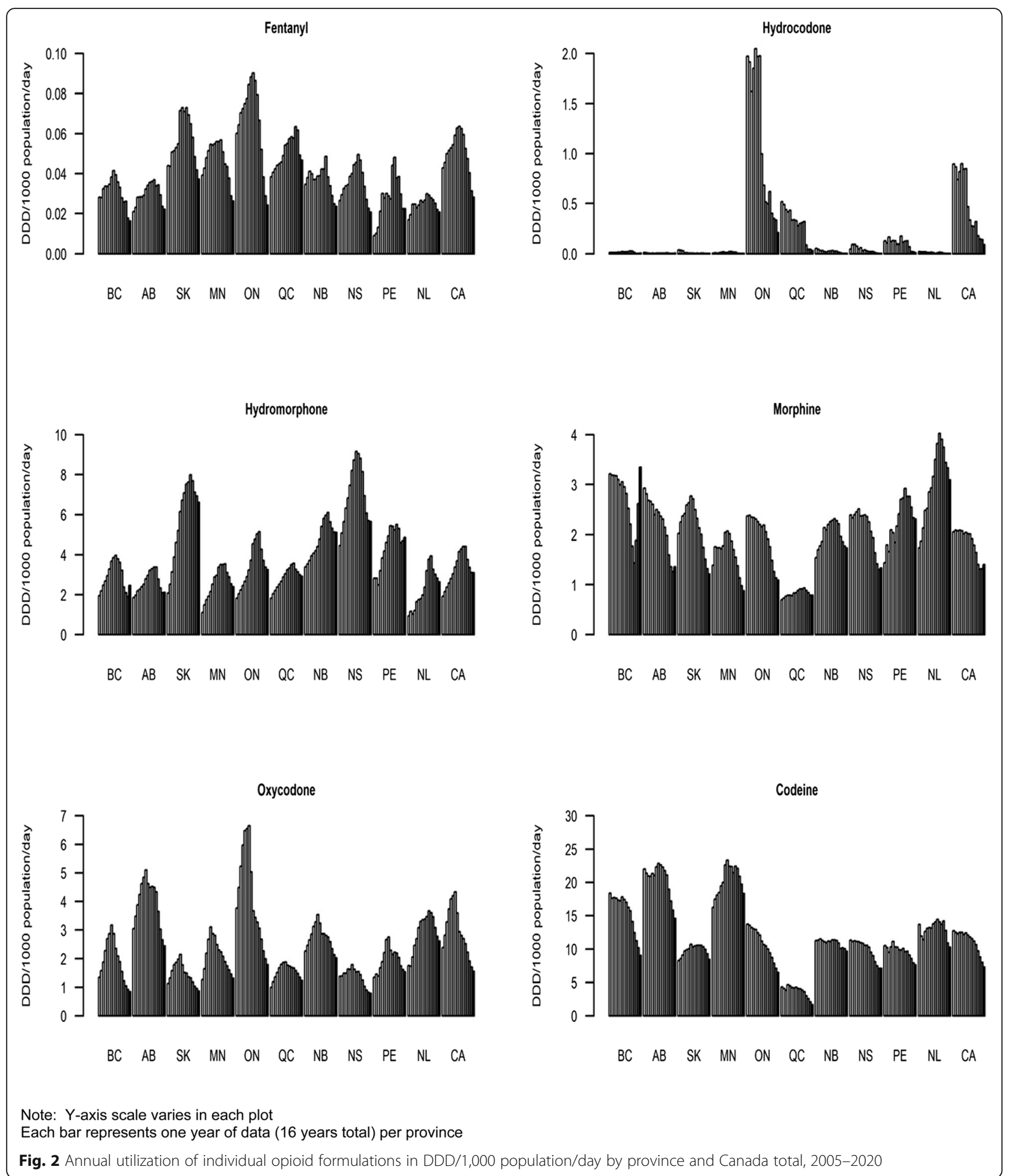

Weak opioids [see Fig. 2 for data visualization]

The majority of provinces reported relatively steady levels in weak opioid (codeine) dispensing with most peak levels in 2011/2012; subsequently, weak opioid dispensing declined in all provinces, and each province except one (SK) reported lower weak opioid dispensing in 2020 compared with 2005. In each year, the inter-provincial range of weak opioid dispensing rates differed by at least $300 \%$. 


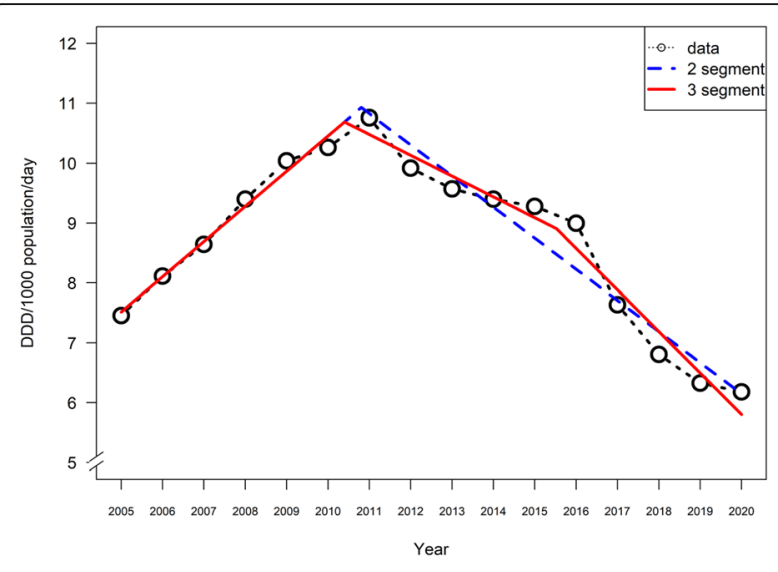

Fig. 3 Two- and three-segment models of 'strong opioid' utilization in Canada, 2005-2020

Multilinear (segmented regression) analysis [see Fig. 3 for results visualization]

Visual inspection of the over-time pattern for strong opioid dispensing (see above) for Canada total suggests an overall non-linear inversion shape, yet it is unclear whether this may involve additional segments. On this basis, the segmented regression analysis confirmed a strictly linear model to be not statistically significant (adjusted R-square: -0.05). A four-segment model (using possible breakpoints at 2008, 2013, and 2017) failed to converge. A three-segment model (breakpoints: 2010 and 2016) was statistically significant (adjusted R-square: 0.96), based on an increasing linear segment running from 2005 to 2010/11, a decreasing linear segment from $2010 / 11$ to $2015 / 16$, and then a steeper decreasing linear segment from 2015/16 to 2020. A two-segment model (breakpoint: 2012) was also statistically significant (Rsquare: 0.94), based on an increasing linear segment from 2005 to 2011, followed by a decreasing linear segment from 2011 to 2020. Of the models examined, the three-segment model fit the observed data best with an AIC value of 12.4, followed by the two-segment model (AIC: 17.0).

\section{Discussion}

We characterized quantitative and qualitative patterns and trends in medical opioid dispensing in Canada, with focus on its ten provinces, for the period 2005-2020. These analyses - extending previous Canada-based examinations - are worthwhile towards assessing both the evolution and drivers of medical opioid utilization in Canada as appear to represent and complete a distinct 'era', yet also more broadly given Canada's status as a global high-consumer nation $[13,50,51]$.

The first, main observation is that over the study period, Canada underwent a marked bi-partial evolution - concretely a stark increase-to-decrease reversal pattern
- of strong opioid utilization. In aggregate, its strong opioid utilization initially increased by almost $50 \%$ (2005$2011 / 12$ ), and subsequently decreased by a similar proportion (2011/12-2020) to an overall lower level compared to 2005. In other words, the overall Canada-wide population exposure for opioids first increased, and then decreased by about half its total volume (in DDD), within just a few years. Such a pronounced rise-and-fall development in the system-wide utilization of controlled psychotropic medications, or any medical intervention geared to a chronic disease (here mainly: pain) with overall stable prevalence in the population ought to be considered highly unusual, if not exceptional. These developments naturally seek for analytic understanding and contextualization of both the essential drivers behind this starkly bi-directional pattern as well as their impacts.

Our analyses begin at a point-in-time (2005) following both increasing national and international attention to 'chronic pain' as a prevalent, but inadequately treated health condition $[1,52-54]$. These contexts, jointly with the emergence of new medical practice guidelines advocating for more liberal and generous opioid pharmacotherapy use especially in the context of pain care, and the rapidly expanding availability of new and potent opioid medications (e.g., slow-release oxycodone) evidently facilitated a substantive increase in medical opioid prescribing and expanding population exposure in Canada within just a few years $[7,8,51]$. Yet, by the overall 'peak' in opioid utilization (2011/2012) it became both increasingly evident that the safety and efficacy of strong opioids widely used for pain-based pharmacotherapy care had been mis-assessed, and that the extensive increases in strong opioid prescribing were associated with extensive collateral harms in the population $[8,21,55]$. Concretely, mounting evidence indicated substantive increases in opioid-related non-medical use, morbidity (e.g., hospitalizations) and mortality (e.g., poisoning deaths) in Canada; for several of the main adverse outcome indicators, strong correlations with populationlevels of prescription opioid dispensing were statistically confirmed, meaning that these harm outcomes increased in direct correlation with the changing volumes of opioids available in the population $[15,56,57]$.

As suggested by the results of our 'segmented regression' analyses, the timepoint of the pan-Canadian delisting of slow-release oxycodone ('Oxycontin') from provincial formularies (2012) as an initial, system-wide intervention to reduce strong opioid availability marked an initial major inversion point towards decreasing strong opioid dispensing $[23,24]$. This intervention resulted in some lateral shifts in specific types of strong opioids prescribed (e.g., from oxycodone to hydromorphone, fentanyl) yet appears to have triggered an overall 
system-wide change and reduction effect in opioid utilization. This particular intervention was further complemented - depending on provincial setting or opioid drug type - by a range of additional (many provinciallybased) restricting measures especially for high-risk opioid utilization in subsequent years (e.g., prescription monitoring program expansion, limitations on high-dose formulations) as selectively assessed for their deceleration impact, creating an aggregately more restrictive opioid prescribing environment in Canada $[22,26,50$, 58-60].

The second 'breakpoint' identified, around 2016/17, may be identified to coincide with the lead-up to and the introduction of new Canadian guidelines for chronic pain treatment tabled in 2017; these new guidelines followed a corresponding set of new US-based guidelines presented just somewhat earlier by the CDC [2016], which already had received substantial attention and select regulatory uptake in Canadian jurisdictions (e.g., BC) with demonstrated reduction effects on opioid prescribing [31, 61-63]. The new Canada-based guidelines conveyed a paradigmatically different spirit and message from their predecessors, advising towards a generally restrained and cautious, largely 'last resort' approach for the utilization of strong opioid pharmacotherapy in the context of pain care [64-67].

The stark inversion developments in strong opioid utilization observed in Canada, to a substantial extent, mirror developments in the US, where rising and exceptionally high levels of strong opioid dispensing reverted to decrease following a combination intensified regulatory, monitoring and enforcement interventions [68-70]. Specifically, the implementation of the new CDC opioid prescribing guideline (2016) has been assessed to be associated with significant decreases in opioid prescribing in the US [71, 72]. While Canada traditionally has also been a high-consumer country for codeine ('weak') opioid products, the observed utilization patterns somewhat follow those for strong opioids. Their utilization, somewhat similarly, also begins to decline around 2010/11, albeit without formal interventions but a rather increasingly restrictive awareness and climate in the medical-scientific community emphasizing their limited efficacy and safety, and the subsequent need for reductions in utilization or for banning use altogether [7375].

Overall, the observed reversing patterns especially in levels of strong opioid dispensing within just a few years in Canada are remarkable, but also reflect the starkly evolving, or even contradictory evidence that have been informing and guiding related medical views and practices during this time. While available scientific literature considered strong opioids as generally 'effective and safe' for pain therapy in the early 2000 s, and their use was systematically promoted by pharmaceutical producers and prescribers alike on this basis, subsequently evolving evidence increasingly underlined limitations and risks $[30,76,77]$. Another influencing factor towards change outside formal policy or regulatory measures involves wider socio-cultural forces, for example, mass media or investigative reports that have focused on the emerging opioid crisis and its facets in Canada post-2012 [78]. These likely also contributed to changing broader public awareness and vigilance, and professional practices in regards to opioids and their use.

Further noteworthy based on the pharmacoepidemiologic data presented is the degree of heterogeneity specifically of province-based patterns and trends in strong opioid dispensing in Canada over time. In any given year, the range of inter-provincially highest and lowest strong opioid dispensing levels reaches a difference of (nearly) $100 \%$. Of note, many - while not all - of the 'lows' in strong opioid dispensing are recorded by Quebec, Canada's socio-culturally distinct francophone province, whereas many 'highs' occurred in Ontario (Quebec's directly adjacent neighbor, and Canada's most populous province). Moreover, the patterns of strong opioid dispensing in several - especially smaller Eastern - provinces inverted to decreasing trends only with a few years' delay. While Canada is a confederation where matters of health regulation and practice are predominantly controlled by the provinces, such stark contrasts within the same nation providing for principles of universal healthcare are worth underscoring [79]. Therefore, the determinants of these inter-provincial differences may include pronvincially-based regulatory system factors and differences (e.g., as related to provincial drug formularies, medical practice regulations, prescription drug monitoring etc.) but may also involve more 'soft' factors like medical practice culture, norms or training [25, 80-82]. The drivers between these distinct intraCanadian heterogeneities in opioid utilization should be more systematically examined by appropriate methods and data.

The starkly contrasting patterns of opioid utilization in Canada observed raise basic questions in regards to their - direct and indirect - impacts and effects on relevant health outcomes. While the initial increases in opioid utilization were driven by high rates of chronic pain and related care system deficiencies, there is discernably little concrete evidence that the substantive expansions in opioid utilization through the early 2000s has led to concrete improvements in pain care quality or outcomes [17, 83-85]. The recently established (2018) 'Canadian Pain Task Force assesses a continuously unfavourable and inadequate picture of the state of pain and related care - characterizing it as "a public health emergency in need of action" as recently as 2021 - that appears little 
different from the situation observed in the early 2000s [35]. Conversely, various (mostly qualitative/local) studies have documented how current chronic pain patients receiving opioid pharmacotherapy have been forced to taper off their opioid medications, or experienced increasing barriers towards opioid medications access in contexts of recent, increasingly restrictive opioid control environments [86-88]. Thus, the overall benefits of the extensive expansions, and subsequent contraction of strong opioid availability as a distinct chapter in health policy practice in Canada appear to be marked by fundamental questions.

Moreover, the substantive un-intended adverse consequences from extensively high population-level opioid exposure, including high rates of non-medical opioid use, opioid-related morbidity (hospitalizations, treatment admissions) and especially mortality (poisoning fatalities) including adverse impacts on population life expectancy have entailed an exceptional burden of adverse outcomes [15, 34, 89-92]. Most recently, Canada's opioid-related poisoning death rate rapidly rose from $7.8 / 100,000$ (2016) to $17.0 / 100,000$ (2020), translating to a total of 6,214 opioid-related fatalities in 2020 and indicating similar rates to those recorded in the US [34, 93]. While the dramatic increases in fatalities have been attributed mostly to illicit/synthetic opioids, some analyses suggest that these drugs proliferated partly in response to 'supply shocks/gaps' following the rapid and substantive reductions in prescription opioid supply available for nonmedical use despite persistent demand [33, 94, 95]. On this basis, the policy 'case study' of the marked inversion of strong opioid utilization in Canada, as documented, have come with distinctly mixed, including considerable adverse impacts relevant for overall population health $[96,97]$.

Further to the data presented, $\mathrm{BC}$ notably represents an outlier province for recent developments in opioid dispensing, in that it features marked re-increases in strong opioid (i.e., morphine, hydromorphone) utilization in very recent (2018-2020) years. These increases appear mainly driven by a growing number of 'safer opioid supply' programs recently initiated in BC (Vancouver) that provide individuals involved with highrisk opioid (e.g., illicit fentanyl or analogues) exposure with less toxic, prescription-grade strong opioid supply (e.g., hydromorphone, sustained-release morphine pills) as a public health measure towards reducing the acute risk for opioid overdose and death [98-100]. On this basis, somewhat ironically, strong opioid dispensing and availability has been re-expanding mainly to remedy the adverse public health consequences - directly or indirectly - facilitated by previous over-exposure and subsequent rapid restrictions in pharmaceutical opioid supply [94, 95, 97]. It also deserves mention that our data extend to 2020, the first year of the COVID-19 pandemic, which has distinctly influenced psychoactive substance use and may have influenced prescription opioid utilization patterns in different while uncertain ways in that particular year. Specifically, there may have been increased demand for or use of prescription opioids (e.g., for pain or other adverse symptoms) due to COVID-19 related circumstances, yet simultaneously increased access barriers and practice changes to health care provision may have reduced medication use [101-103].

The present study and analyses include several limitations. The community-pharmacy sample-based data used for opioid dispensing calculation does not capture other dispensing points (e.g., hospitals, internet pharmacies), and so may involve underestimations. DDD as a comparative opioid measurement metric is limited in reliability, but similar in its limitations to that of other measures (e.g., morphine equivalents) and superior to crude indicators like numbers of prescriptions [42, 104]. The segmented regression may be limited by the limited number of data years available for the analyses. Moreover, segmented regression fits linear segments while it is possible that in some cases non-linear segments could provide a better fit for the data, a possibility not examined here. In addition, results can be influenced by the choice of initial values but this is often mitigated by basing the selection on examination of initial scatter plots [48]. The population-level dispensing data do not include the three Canadian territories, and so formally do not represent the Canada 'total'; however, the territories only include $<0.5 \%$ of the total Canadian population. Analyses for Canada totals of opioid dispensing are population-weighted, and so are dominated by trends in the more populous (e.g., ON) provinces.

\section{Conclusions}

We have characterized an era of intensive rise-and-fall in opioid dispensing, while featuring marked interprovincial heterogeneity, in Canada over the (brief) period 2005-2020. This case study raises fundamental questions for health policy making, and specifically opioid medications utilization and control in contexts of pain care, psychotropic medications use and public health for Canada, but beyond for other jurisdictions aiming to develop appropriate and effective health policy approaches in these realms. Essentially, Canada in regards to opioid utilization, after a pronounced period of 'up-and-down', finds itself back where it was in the early 2000s, yet without substantive evidence for marked improvements in pain care quality or outcomes while recording extensive adverse effects for public health from extensive population-level opioid exposure. The stark oscillation developments observed, and related consequences experienced over the past 20 years naturally 
cannot be corrected or reversed now. Looking forward, it will be essential for Canada - within the complexities of its health care and policy systems - to find a more stable and evidence-informed state or equilibrium that better balances evidence-based pain care and related clinical opioid utilization needs for those individuals who require them, while preventing undue opioid exposure and reducing related adverse consequences for the general population and the benefit of public health. To some extent, other industrialized nations (e.g., select European countries or New Zealand) have taken more restrained and cautious approaches to medical opioid utilization and - even in contexts of increases in utilization - have experienced overall lower levels of related harms, and therefore may offer useful case studies or guiding evidence to Canada or other jurisdictions in these respects going forward [105-107].

\section{Abbreviations}

DDD: Defined Daily Doses; US: United States; DDD: Defined Daily Doses; BC: British Columbia; AB: Alberta; SK: Saskatchewan; MN: Manitoba; ON: Ontario; QC: Quebec; NB: New Brunswick; NS: Nova Scotia; PE: Prince Edward Island; NL: Newfoundland and Labrador; CA: Canada; AIC: Akaike information criterion; CDC: Center for Disease Control

\section{Acknowledgements}

The authors thank Lenka Vojtila-Valenzuela for her assistance in the manuscript preparation and submission.

\section{Authors' contributions}

BF conceptualized the study and led the initial and subsequent revision drafts of the paper. WJ lead the development of the analyses plan and conducted the statistical analyses. All authors (WJ, RK, BF) contributed to methodological adjustments, review and interpretation of data and results, and provided substantial intellectual contributions to the content of the paper. All authors approved the final manuscript submitted.

\section{Funding}

The authors acknowledge research support from the Canadian Institutes of Health Research (CIHR; grant \#SAF-94814,) as well as from the Hugh Green Foundation Chair in Addiction Research, held at the Faculty of Medical and Health Sciences, University of Auckland, New Zealand. Neither funder entities nor providers of data mentioned had any involvement in or influence over the study design, analyses, reporting or interpretation of the data.

\section{Availability of data and materials}

The raw data on prescription opioid dispensing in Canada were commercially obtained IQVIA Solutions Canada Inc., with all subsequent data processing and analyses solely conducted by the authors. Population data statistics used for the analyses were obtained from Statistics Canada. The external data sources/providers had no involvement or influence in any steps of the analysis development, results generation or data interpretation, or other aspects of the manuscript.

\section{Declarations}

Ethics approval and consent to participate Not applicable.

\section{Consent for publication}

Not applicable.

\section{Competing interests}

The authors have no competing interests.

\section{Author details}

${ }^{1}$ Centre for Applied Research in Mental Health and Addiction (CARMHA), Faculty of Health Sciences, Simon Fraser University, Suite 2400, 515 W. Hastings Street, British Columbia, Vancouver, Canada. ${ }^{2}$ Faculty of Medical and Health Sciences, University of Auckland, 85 Park Road, Auckland 1023 Grafton, New Zealand. ${ }^{3}$ Department of Psychiatry, University of Toronto, 250 College Street, Toronto, Ontario, Canada. ${ }^{4}$ Department of Psychiatry, Federal University of São Paulo (UNIFESP), R. Sena Madureira, 1500 - Vila Clementino, São Paulo, Brazil.

Accepted: 23 July 2021

Published online: 14 September 2021

\section{References}

1. Moulin DE, Clark AJ, Speechley M, Morley-Forster PK. Chronic pain in Canada-prevalence, treatment, impact and the role of opioid analgesia. Pain Res Manag. 2002;7(4):179-84.

2. Schopflocher D, Taenzer P, Jovey R. The prevalence of chronic pain in Canada. Pain Res Manag. 2011;16(6):445-50.

3. Tompkins DA, Hobelmann JG, Compton P. Providing chronic pain management in the "Fifth Vital Sign" Era: Historical and treatment perspectives on a modern-day medical dilemma. Drug Alcohol Depend. 2017;173:11-21.

4. Lanser P, Gesell S. Pain management: the fifth vital sign. Healthc Benchmarks. 2001;8(6):68-70.

5. Morone NE, Weiner DK. Pain as the fifth vital sign: exposing the vital need for pain education. Clin Ther. 2013;35(11):1728-32.

6. Morley-Forster PK, Clark AJ, Speechley M, Moulin DE. Attitudes toward opioid use for chronic pain: a Canadian physician survey. Pain Res Manag. 2003;8(4):189-94.

7. Jovey RD, Ennis J, Gardner-Nix J, Goldman B, Hays H, Lynch M, et al. Use of opioid analgesics for the treatment of chronic noncancer pain-a consensus statement and guidelines from the Canadian Pain Society, 2002. Pain Res Manag. 2003;8(Suppl A):3A-14A.

8. Dhalla IA, Mamdani MM, Sivilotti ML, Kopp A, Qureshi O, Juurlink DN. Prescribing of opioid analgesics and related mortality before and after the introduction of long-acting oxycodone. CMAJ. 2009;181(12):891-6.

9. Furlan AD, Sandoval JA, Mailis-Gagnon A, Tunks E. Opioids for chronic noncancer pain: a meta-analysis of effectiveness and side effects. CMAJ. 2006;174(11):1589-94.

10. Martin TL, Woodall KL, McLellan BA. Fentanyl-related deaths in Ontario, Canada: toxicological findings and circumstances of death in 112 cases (2002-2004). J Anal Toxicol. 2006;30(8):603-10.

11. Lexchin J, Kohler JC. The danger of imperfect regulation: OxyContin use in the United States and Canada. Int J Ris Saf in Med. 2011;23(4):233-40.

12. Van Zee A. The promotion and marketing of oxycontin: commercial triumph, public health tragedy. Am J of Pub Health. 2009;99(2):221-7.

13. International Narcotics Control Board (2021) Narcotic Drugs - Technical Report Vienna. INCB, Austria Available: https://www.incb.org/incb/en/na rcotic-drugs/Technical_Reports/narcotic_drugs_reports.html. Retrieved: June 12,2021

14. International Narcotics Control Board. Report of the International Narcotics Control Board on the Availability of Internationally Controlled Drugs: Ensuring Adequate Access for Medical and Scientific Purposes. Vienna: INCB, United Nations; 2010.

15. Fischer B, Argento E. Prescription opioid related misuse, harms, diversion and interventions in Canada: a review. Pain Physician. 2012;15(3 Suppl): ES191-203.

16. Fischer B, Goldman B, Rehm J, Popova S. Non-medical use of prescription opioids and public health in Canada. Can J of Pub Health. 2008;99(3):182-4.

17. Boulanger A, Clark AJ, Squire P, Cui E, Horbay G. Chronic pain in Canada: have we improved our management of chronic noncancer pain? Pain Res Manag. 2007;12(1):39-47.

18. Fischer B, Nakamura N, Rush B, Rehm J, Urbanoski K. Changes in and characteristics of admissions to treatment related to problematic prescription opioid use in Ontario, 2004-2009. Drug Al Depend. 2010;109(13):257-60.

19. Public Health Ontario. Interactive Opioid Tool. Ottawa: Public Health Ontario. Available: https://www.publichealthontario.ca/en/data-and-analysis/ substance-use/interactive-opioid-tool. Retrieved: 12 June 2021. 
20. Dhalla IA, Mamdani MM, Gomes T, Juurlink DN. Clustering of opioid prescribing and opioid-related mortality among family physicians in Ontario. Can Fam Physician. 2011:57(3):e92-e6.

21. Fischer B, Gooch J, Goldman B, Kurdyak P, Rehm J. Non-medical prescription opioid use, prescription opioid-related harms and public health in Canada: an update 5 years later. Can J Public Health. 2014;105(2):146-9.

22. Fischer B, Rehm J, Tyndall M. Effective Canadian policy to reduce harms from prescription opioids: learning from past failures. CMAJ. 2016;188(17-18):1240-4.

23. Gomes T, Mastorakos A, Paterson JM, Sketris I, Caetano P, Greaves S, et al. Changes in the dispensing of opioid medications in Canada following the introduction of a tamper-deterrent formulation of long-acting oxycodone: a time series analysis. CMAJ Open. 2017;5(4):E800.

24. Fischer B, Vojtila L, Kurdyak P. 'Delisting'OxyContin ${ }^{\oplus}$ to reduce prescription opioid-related harms in Ontario (Canada) - gauging effects 5 years later. Pharmacoepidemiol Drug Saf. 2017;26(9):1040-3.

25. Furlan AD, MacDougall P, Pellerin D, Shaw K, Spitzig D, Wilson G, et al. Overview of for prescription monitoring/review programs in Canada. Pain Res Manag. 2014;19(2):102-6.

26. Gomes T, Juurlink D, Yao Z, Camacho X, Paterson JM, Singh S, et al. Impact of legislation and a prescription monitoring program on the prevalence of potentially inappropriate prescriptions for monitored drugs in Ontario: a time series analysis. CMAJ Open. 2014;2(4):E256.

27. Canadian Centre on Substance Use and Addiction. First Do No Harm: Responding to Canada's Prescription Drug Crisis (Report) 2013. Available: https://www.ccsa.ca/first-do-no-harm-responding-canadas-prescription-drugcrisis-report. Retrieved: June 12, 2021.

28. Spooner L, Fernandes K, Martins D, Juurlink D, Mamdani M, Paterson JM et al. High-dose opioid prescribing and opioid-related hospitalization: a population-based study. PloS one. 2016;11(12):e0167479.

29. Chou R, Turner JA, Devine EB, Hansen RN, Sullivan SD, Blazina I, et al. The effectiveness and risks of long-term opioid therapy for chronic pain: a systematic review for a National Institutes of Health Pathways to Prevention Workshop. Ann Int Med. 2015;162(4):276-86

30. Busse JW, Schandelmaier S, Kamaleldin M, Hsu S, Riva JJ, Vandvik PO, et al. Opioids for chronic non-cancer pain: a protocol for a systematic review of randomized controlled trials. Syst Rev. 2013;2(1):66.

31. Busse JW, Craigie S, Juurlink DN, Buckley DN, Wang L, Couban RJ, et al. Guideline for opioid therapy and chronic noncancer pain. CMAJ. 2017; 189(18):E659-E66.

32. Fischer B, Vojtila L, Rehm J. The 'fentanyl epidemic'in Canada-Some cautionary observations focusing on opioid-related mortality. Prev Med. 2018;107:109-13.

33. Gomes T, Khuu W, Martins D, Tadrous M, Mamdani MM, Paterson JM, et al. Contributions of prescribed and non-prescribed opioids to opioid related deaths: population based cohort study in Ontario, Canada. BMJ. 2018;362:k3207.

34. Government of Canada. Opioid- and Stimulant-related Harms in Canada. 2021.

35. Government of Canada. Canadian Pain Task Force. Ottawa: Government of Canada; 2021. Available: https://www.canada.ca/en/health-canada/corpora te/about-health-canada/public-engagement/external-advisory-bodies/cana dian-pain-task-force.html. Retrieved: 12 June 2021.

36. IQVIA. Canadian Pharmaceutical T. 2021. Available: https://www.canada.ca/ en/health-canada/corporate/about-health-canada/public-engagement external-advisory-bodies/canadian-pain-task-force.html. Retrieved: 12 June 2021.

37. Jones W, Vojtila L, Kurdyak P, Fischer B. Prescription opioid dispensing in Canada: an update on recent developments to 2018. J Pharm Policy Prac. 2020;13(1):1-6.

38. Canadian Institute for Health Information. Pan-Canadian Trends in the Prescribing of Opioids and Benzodiazepines, 2012 to 2017. Ottawa: $\mathrm{ClHI}$; 2018.

39. Gomes T, Paterson JM, Juurlink DN, Dhalla IA, Mamdani MM. Reformulation of controlled-release oxycodone and pharmacy dispensing patterns near the US-Canada border. Open Med. 2012;6(4):e141.

40. WHO Collaborating Centre for Drug Statistics Methodology. Definition and general considerations: World Health Organization; 2018. Available: https:/www. whocc.no/ddd/definition_and_general_considera/. Retrieved: 12 June 2021.

41. Svendsen K, Borchgrevink P, Fredheim O, Hamunen K, Mellbye A, Dale O. Choosing the unit of measurement counts: the use of oral morphine equivalents in studies of opioid consumption is a useful addition to defined daily doses. Pal Med. 2011;25(7):725-32.
42. Nielsen S, Gisev N, Bruno R, Hall W, Cohen M, Larance B, et al. Defined daily doses (DDD) do not accurately reflect opioid doses used in contemporary chronic pain treatment. Pharmacoepidemiol Drug Saf. 2017;26(5):587-91.

43. Statistics Canada. Population estimates on July 1 st, by age and sex: Table: 17-10-0005-01; 2021. Available: https://www150.statcan.gc.ca/t1/tbl1/en/tv.a ction?pid=1710000501. Retrieved: 12 June 2021.

44. Anekar AA, Cascella M. WHO Analgesic ladder: StatPearls. 2020. Available: https://www.ncbi.nlm.nih.gov/books/NBK554435/. Retrieved: June 12, 2021.

45. Raffa R, Pergolizzi J Jr. A modern analgesics pain 'pyramid'. J Clin Pharm Ther. 2014;39(1):4-6

46. R Core Team. R: A language and environment for statistical computing Vienna, Austria: R Foundation for Statistical Computing; 2021. Available: https://www.R-project.org/. Retrieved: June 12, 2021.

47. Muggeo VM. Segmented: an R package to fit regression models with broken-line relationships. R News. 2008;8(1):20-5.

48. Muggeo VM. Estimating regression models with unknown break-points. Stat Med. 2003:22(19):3055-71.

49. Wikipedia. Segmented Regression; 2021. Available: https://en.wikipedia.org/ wiki/Segmented_regression\#: :text=Segmented\%20regression\%2C\%20a Iso\%20known\%20as,is\%20fit\%20to\%20each\%20interval.\&text=The\%2 Oboundaries\%20between\%20the\%20segments\%20are\%20breakpoints. Retrieved: 12 June 2021.

50. Fischer $\mathrm{B}$, Jones $\mathrm{W}$, Rehm J. Trends and changes in prescription opioid analgesic dispensing in Canada 2005-2012: An update with a focus on recent interventions. BMC Health Serv Res. 2014;14(1):90.

51. Fischer B, Jones W, Krahn M, Rehm J. Differences and over-time changes in levels of prescription opioid analgesic dispensing from retail pharmacies in Canada, 2005-2010. Pharmacoepidemiol Drug Saf. 2011;20(12):1269-77.

52. Peng $P$, Choiniere $M$, Dion $D$, Intrater $H$, LeFort $S$, Lynch $M$, et al. Challenges in accessing multidisciplinary pain treatment facilities in Canada. Can J Anaes. 2007;54(12):977.

53. Goldberg DS, McGee SJ. Pain as a global public health priority. BMC Public Health. 2011;11(1):1-5.

54. Taylor AL, Gostin LO, Pagonis KA. Ensuring effective pain treatment: a national and global perspective. JAMA. 2008;299(1):89-91.

55. Dhalla IA, Persaud N, Juurlink DN. Facing up to the prescription opioid crisis. BMJ. 2011;343:23-36.

56. Fischer B, Jones W, Urbanoski K, Skinner R, Rehm J. Correlations between prescription opioid analgesic dispensing levels and related mortality and morbidity in Ontario, Canada, 2005-2011. Drug Alc Rev. 2014;33(1):19-26.

57. Fischer B, Jones W, Rehm J. High correlations between levels of consumption and mortality related to strong prescription opioid analgesics in British Columbia and Ontario, 2005-2009. Pharmacoepidemiol Drug Saf. 2013;22(4):438-42.

58. Martins D, Khuu W, Tadrous M, Juurlink DN, Mamdani MM, Paterson JM, et al. Impact of delisting high-strength opioid formulations from a public drug benefit formulary on opioid utilization in Ontario, Canada. Pharmacoepidemiol Drug Saf. 2019;28(5):726-33.

59. Schleihauf E, Crabtree K, Dohoo C, Fleming S, McPeake H, Bowes M. At-aglance-Concurrent monitoring of opioid prescribing practices and opioidrelated deaths: the context in Nova Scotia, Canada. Health Promot Chronic Dis Prev Can. 2018;38(9):334

60. Canadian Institute for Health Information. Opioid Prescribing in Canada: How are Practices Changing? Ottawa: $\mathrm{ClHI} ; 2019$.

61. Dowell D, Haegerich TM, Chou R. CDC guideline for prescribing opioids for chronic pain-United States, 2016. JAMA. 2016;315(15):1624-45.

62. Crabtree A, Rose C, Chong M, Smolina K. Effects of the new prescribing standards in British Columbia on consumption of opioids and benzodiazepines and z drugs. Can Fam Physician. 2019;65(5):e231-e7.

63. Morrow RL, Bassett K, Wright JM, Carney G, Dormuth CR. Influence of opioid prescribing standards on drug use among patients with long-term opioid use: a longitudinal cohort study. CMAJ Open. 2019;7(3):E484.

64. Pergolizzi JV Jr, Raffa RB, Zampogna G, Breve F, Colucci R, Schmidt WK, et al. Comments and Suggestions from Pain Specialists Regarding the CDC's Proposed Opioid Guidelines. Pain Pract. 2016;16(7):794-808.

65. Renthal W. Seeking balance between pain relief and safety: CDC issues new opioid-prescribing guidelines. JAMA Neurol. 2016;73(5):513-4.

66. Ballantyne JC, Murinova N, Krashin DL. Opioid guidelines are a necessary response to the opioid crisis. Clin Pharm Ther. 2018;103(6):946-9.

67. Clarke H, Bao J, Weinrib A, Dubin RE, Kahan M. Canada's hidden opioid crisis: the health care system's inability to manage high-dose opioid 
patients: Fallout from the 2017 Canadian opioid guidelines. Can Fam Physician. 2019;65(9):612-4.

68. Schuchat A, Houry D, Guy GP. New data on opioid use and prescribing in the United States. JAMA. 2017;318(5):425-6.

69. Guy GP Jr, Zhand K, Bohm MK, Losby J, Lewis B, Young R, et al. Vital signs: changes in opioid prescribing in the United States, 2006-2015. MMWR. 2017;66(26):697.

70. Chang H-Y, Lyapustina T, Rutkow L, Daubresse M, Richey M, Faul M, et al. Impact of prescription drug monitoring programs and pill mill laws on high-risk opioid prescribers: a comparative interrupted time series analysis. Drug Alc Depend. 2016;165:1-8.

71. Bohnert AS, Guy GP Jr, Losby JL. Opioid prescribing in the United States before and after the Centers for Disease Control and Prevention's 2016 opioid guideline. Ann of Int Med. 2018;169(6):367-75.

72. Quan AML, Wilson LA, Mithani SS, Zhu DT, Bota AB, Wilson K. Reporting on the opioid crisis (2000-2018): role of The Globe and Mail, a Canadian English-language newspaper in influencing public opinion. Harm Red J. 2020;17(1):1-11.

73. Tobias JD, Green TP, Coté CJ. Codeine: time to say "no". Pediatrics. 2016; 138(4):E1-7.

74. MacDonald N, MacLeod SM. Has the time come to phase out codeine? CMAJ. 2010;182(17):1825.

75. Mackinnon J. Tighter regulations needed for over-the-counter codeine in Canada. Can Pharm J. 2016;149(6):322-4

76. Ballantyne JC. Opioids for the treatment of chronic pain: mistakes made, lessons learned, and future directions. Anasth Analg. 2017;125(5):1769-78.

77. Vowles E, McEntee M, Siyahhan Julnes P, Frohe T, Ney J, van der Goes D. Rates of opioid misuse, abuse, and addiction in chronic pain: a systematic review and data synthesis. Pain. 2015;156(4):569-76.

78. Borwein A, Kephart G, Whelan E, Asbridge M. Prescribing practices amid the OxyContin crisis: examining the effect of print media coverage on opioid prescribing among physicians. J Pain. 2013;14(12):1686-93.

79. Allin S, Rudoler D. The Canadian health care system: 2017. Int Prof Health Care Syst. 2015:21(3):36-51

80. Demers V, Melo M, Jackevicius C, Cox J, Kalavrouziotis D, Rinfret S, et al. Comparison of provincial prescription drug plans and the impact on patients' annual drug expenditures. CMAJ. 2008;178(4):405-9.

81. Hirschkorn KA, Andersen R, Bourgeault IL. Canadian family physicians and complementary/alternative medicine: the role of practice setting, medical training, and province of practice. Can Rev Sociol. 2009;46(2):143-59.

82. Roy É, Côté RJ, Hamel D, Dubé P-A, Langlois É, Labesse ME, et al. Opioid prescribing practices and training needs of Québec family physicians for chronic noncancer pain. Pain Res Manag. 2017;2017.

83. Lynch ME. The need for a Canadian pain strategy. Pain Res Manag. 2011; 16(2):77-80

84. Shupler MS, Kramer JK, Cragg JJ, Jutzeler CR, Whitehurst DG. Pan-Canadian estimates of chronic pain prevalence from 2000 to 2014: a repeated crosssectional survey analysis. J Pain. 2019;20(5):557-65.

85. Saïdi H, Pagé MG, Boulanger A, Ware MA, Choinière M. Effectiveness of long-term opioid therapy among chronic non-cancer pain patients attending multidisciplinary pain treatment clinics: A Quebec Pain Registry study. Can J Pain. 2018;2(1):113-24.

86. Antoniou T, Ala-Leppilampi K, Shearer D, Parsons JA, Tadrous M, Gomes T. "Like being put on an ice floe and shoved away": A qualitative study of the impacts of opioid-related policy changes on people who take opioids. Int J of Drug Policy. 2019;66:15-22.

87. Kaboré J-L, Dassieu L, Roy É, Jutras-Aswad D, Bruneau J, Pagé MG, et al. Prevalence, Characteristics, and Management of Chronic Noncancer Pain Among People Who Use Drugs: A Cross-Sectional Study. Pain Med. 2020;21(11):3205-14.

88. Dassieu L, Kaboré J-L, Choinière M, Arruda N, Roy É. Chronic pain management among people who use drugs: A health policy challenge in the context of the opioid crisis. Int J Drug Policy. 2019;71:150-6.

89. Fischer B. Prescription opioid use, harms and interventions in Canada: a review update of new developments and findings since 2010. Pain Physician. 2015;18:E605-E14.

90. Vojtila L, Pang M, Goldman B, Kurdyak P, Fischer B. Non-medical opioid use, harms and interventions in Canada - a 10-year update on an unprecedented and unabating substance use-related public health crisis. Drugs (Abingdon Engl). 2019;27(2):118-22.

91. Belzak L, Halverson J. Evidence synthesis-The opioid crisis in Canada: a national perspective. Health Promot Chronic Dis Prev Can. 2018;38(6):224.
92. Orpana Heather M, Lang Justin J, George Diana HJ. At-a-glance-The impact of poisoning-related mortality on life expectancy at birth in Canada, 2000 to 2016. Health Promot Chronic Dis Prev Can. 2019;39(2):56.

93. Wilson N Drug and Opioid-Involved Overdose Deaths_-United States, 2017-2018. MMWR. 2020;69:290-7.

94. Fischer B, Pang M, Tyndall M. The opioid death crisis in Canada: crucial lessons for public health. Lancet Public Health. 2018;4(2):e81-e2.

95. Fischer B, Pang M, Jones W. The opioid mortality epidemic in North America: do we understand the supply side dynamics of this unprecedented crisis? J Sub Abuse Treat Prev Policy. 2020;15(1):1-8.

96. Babor TF, Caulkins J, Fischer B, Foxcroft D, Medina-Mora ME, Obot I, et al. Drug policy and the public good: a summary of the second edition. Addiction. 2019;114(11):1941-50.

97. Fischer B, Wood E. A decade of extreme oscillations in opioid control and availability: implications for public health in a Canadian setting. J Pub Health Policy. 2020;41:214-20.

98. Ivsins A, Boyd J, Mayer S, Collins A, Sutherland C, Kerr T, et al. Barriers and facilitators to a novel low-barrier hydromorphone distribution program in Vancouver, Canada: a qualitative study. Drug Alc Depend. 2020;216:102-23.

99. Tyndall M. A safer drug supply: a pragmatic and ethical response to the overdose crisis. CMAJ. 2020;192(34):E986-E7.

100. BC Centre for Disease Control. Overdose Response Indicator Report Vancouver: BC Centre for Disease Control; 2020.

101. Kumar N, Janmohamed K, Nyhan K, Martins SS, Cerda M, Hasin D, et al. Substance use and substance use disorder, in relation to COVID-19: protocol for a scoping review. Syst Rev. 2021:10(1):1-6.

102. Rogers AH, Shepherd JM, Garey L, Zvolensky MJ. Psychological factors associated with substance use initiation during the COVID-19 pandemic. Psych Res. 2020;293:113407.

103. Alexander GC, Stoller KB, Haffajee RL, Saloner B. An epidemic in the midst of a pandemic: opioid use disorder and COVID-19. Am College Phys. 2020:173: $57-8$.

104. Nielsen S, Degenhardt L, Hoban B, Gisev N. A synthesis of oral morphine equivalents (OME) for opioid utilisation studies. Pharmacoepidemiol Drug Saf. 2016;25(6):733-7.

105. Fischer B, Daldegan-Bueno D, Jones W. Comparison of crude populationlevel indicators of opioid use and related harm in New Zealand and Ontario (Canada). Pain Therapy. 2021;10(1):15-23.

106. Verhamme KM, Bohnen AM. Are we facing an opioid crisis in Europe? Lancet Public Health. 2019;4(10):e483-e4.

107. Häuser W, Buchser E, Finn D, Dom G, Fors E, Heiskanen T, et al. Is Europe also facing an opioid crisis? - A survey of European Pain Federation chapters. Euro J Pain. 2021;25:1760-9.

\section{Publisher's Note}

Springer Nature remains neutral with regard to jurisdictional claims in published maps and institutional affiliations.

Ready to submit your research? Choose BMC and benefit from:

- fast, convenient online submission

- thorough peer review by experienced researchers in your field

- rapid publication on acceptance

- support for research data, including large and complex data types

- gold Open Access which fosters wider collaboration and increased citations

- maximum visibility for your research: over $100 \mathrm{M}$ website views per year

At $\mathrm{BMC}$, research is always in progress.

Learn more biomedcentral.com/submissions 